\title{
Symposium 2 Newer aspects of micronutrients in at risk groups
}

\section{New metabolic roles for selenium}

\author{
BY JOHN R. ARTHUR \\ Division of Biochemical Sciences, Rowett Research Institute, Greenburn Road, Bucksburn, \\ Aberdeen $A B 29 S B$

\section{AND GEOFFREY J. BECKETT} \\ University Department of Clinical Biochemistry, The Royal Infirmary, Edinburgh EH3 $9 Y W$
}

Adequate supplies of the micronutrient Se are required for normal health in both man and animals. Since the recognition of the essentiality of Se, decreased dietary Se supplies have been associated with a large number of clinical conditions. Additionally, Se supplementation of rodents has a beneficial role in the prevention of certain chemicallyinduced cancers. These findings have been the subject of a number of recent publications and are summarized in Table 1.

The first functional selenoprotein to be identified was cytosolic glutathione peroxidase (cGSHPx; Rotruck et al. 1973). Despite the recognition that a number of proteins could be specifically-labelled with ${ }^{75} \mathrm{Se}$, for several years cGSHPx remained the only identified, functional selenoprotein (Behne et al. 1988; Evenson \& Sunde, 1988; Bansal et al. 1991). Consequently attempts were made to explain the role of Se in the prevention of many apparently unrelated diseases as antioxidant effects of cGSHPx. Also, since cGSHPx in blood and tissues reflects dietary Se intake the enzyme activity has been used as an index of nutritional Se status (Hoekstra, 1975; Combs \& Combs, 1986).

In recent years, however, several more selenoproteins have been characterized either by purification and sequencing of the protein and/or by cloning and sequencing of cDNAs. The purpose of the present short review is to describe some of these newly identified selenoproteins and how they may function in conferring the nutritional essentiality of Se.

Table 1. Some conditions and functional changes associated with selenium
1. Nutritional myopathy and other deficiency diseases in farm animals
2. Cardiomyopathy and other deficiency diseases in humans
(Keshan disease and Kashin Beck disease)
3. Thyroid hormone and I metabolism
4. Deficiency caused by TPN
5. Effects on the immune response?
6. Anti-cancer effects of supplementation?
7. Relationships to CHD etc.?
8. Changes in mood and well-being?

\footnotetext{
For further details see: Boyne \& Arthur, 1986; Combs \& Combs, 1986; Arthur \& Beckett, 1989; Bansal et al. 1990, 1991; Benton \& Cook, 1990, 1991; Turner \& Finch, 1990, 1991; Vanderpas et al. 1990, 1993; Arthur, 1991; Arthur et al. 1993; Corvilain et al. 1993; Lanfear et al. 1993; Ip \& Lisk, 1994.

CHD, coronary heart disease; TPN, total parenteral nutrition.
} 
Table 2. Selenoproteins and selenium-binding proteins which have been purified and/or cloned

1. GSH peroxidase: (a) Cytosolic, $R B C$

(b) Plasma

(c) Phospholipidhydroperoxide

(d) Gastrointestinal

2. Selenoprotein $P$

3. Iodothyronine $S^{\prime}$-deiodinase

4. Sperm capsule selenoprotein

5. Selenoprotein $\mathrm{W}$

6. 58,56 and $14 \mathrm{kDa}$ Se-binding proteins

For further details see: Rotruck et al. 1973; Takahashi et al. 1987, 1990; Yang et al. 1987; Avissar et al. 1989, 1994a; Arthur et al. 1990a,b, 1991, 1993; Berry et al. 1991; Hill et al. 1991; Karimpour et al. 1992; Burk \& Hill, 1993; Lanfear et al. 1993; Sinha et al. 1993; Sunde et al. 1993; Vendeland et al. 1993; Akesson et al. 1994; BrigeliusFlohe et al. 1994.

GSH, glutathione; RBC, erythrocyte.

\section{SELENOPROTEINS}

Studies using in vivo labelling with ${ }^{75}$ Se have shown that there may be up to thirty proteins which retain Se during subsequent purification and separation using sodium dodecylsulphate (SDS) polyacrylamide-gel electrophoresis. The ability of Se to remain bound at $100^{\circ}$ under reducing conditions is taken as evidence of covalent or very strong bonds between trace element and protein rather than a non-specific interaction (Behne et al. 1988; Evenson \& Sunde, 1988; Sunde, 1990, 1994). Ten of these ${ }^{75}$ Se-containing proteins have been further characterized, eight of which contain Se as selenocysteine. The form of Se in Se-binding proteins is not known (Table 2). The range of selenoproteins now identified is consistent with multiple biochemical functions for Se and these are discussed in the rest of the present review.

\section{GLUTATHIONE PEROXIDASES}

The discovery that there are four distinct glutathione peroxidases may go some way to explain the involvement of Se deficiency in the pathogenesis of apparently unrelated clinical conditions. The glutathione peroxidases function in different subcellular compartments and each of the four are impaired by Se deficiency to different degrees. Thus, depending on the sensitivity of each GSHPx to Se supply, loss of activity from a particular tissue or cell compartment could cause a specific organ-related disease (Arthur et al. 1987a).

\section{Cytosolic glutathione peroxidase}

cGSHPx was the first well characterized biochemical function for Se (Rotruck et al. 1973). Since cGSHPx can metabolize $\mathrm{H}_{2} \mathrm{O}_{2}$ and lipid hydroperoxides it is thought to be a component of cell antioxidant systems (Hoekstra, 1975; Sunde, 1994). However, many 
pathophysiological consequences of Se deficiency are not inextricably linked to changes in cGSHPx activity, and in Se-deficient rats hepatic cGSHPx activity may fall to $<1 \%$ of control values without any obvious adverse clinical effects (Reiter \& Wendel, 1983, 1984, 1985; Arthur et al. 1987a,b; Burk, 1989). These observations led to proposals that there were 'non-glutathione peroxidase' functions of Se and that the enzyme may represent a storage form of the trace element (Burk, 1991; Sunde, 1994). However, under specific circumstances cGSHPx can have an antioxidant function. Transgenic cells overexpressing cGSHPx activity are more resistant to peroxide or drug challenge than wild-type cells and the ability of mouse neutrophils to kill ingested Candida albicans correlates with cGSHPx activity in the neutrophils over a 'normal' range of Se status (Arthur et al. 1986; Doroshaw et al. 1991; Mirault et al. 1991). Thus, cGSHPx may only have antioxidant functions under conditions where relatively large amounts of $\mathrm{H}_{2} \mathrm{O}_{2}$ or lipid hydroperoxides are produced in the cell cytosol. Current evidence, therefore, indicates that cGSHPx has both a Se storage and an antioxidant function.

\section{Plasma glutathione peroxidase (plGSHPx)}

plGSHPx, also called extracellular GSHPx, is distinct from cGSHPx both in structure and site of function. Antibodies to purified plGSHPx will not cross react with cGSHPx (Takahashi \& Cohen, 1986; Avissar et al. 1991). Human and rat plGSHPx have been cloned, and hybridization studies indicate that the kidney and lung are the major sites of synthesis (Takahashi et al. 1990; Yoshimura et al. 1991; Avissar et al. 1994a,b). This is supported by studies which show that anephric patients have very low plGSHPx activities with apparently normal plasma Se concentrations. plGSHPx activities are returned to normal after renal transplantation of these patients, without any change in plasma Se concentrations (Avissar et al. 1994b). More detailed hybridization studies showed that plGSHPx mRNA occurred in the proximal tubular epithelial cells and the parietal epithelial cells of Bowman's capsule (Avissar et al. 1994b). Despite the detailed knowledge of plGSHPx structure and synthesis, its function is not known. The glutathione (GSH) substrate for plGSHPx occurs in very low concentrations in the plasma which has led to the suggestion that the enzyme may function other than as a glutathione peroxidase. The concentrations of GSH in the kidney would allow the enzyme to act as a peroxidase and, thus, it may have a specific function in the renal proximal tubules. However, plGSHPx cDNA has a signal sequence and the enzyme is glycosylated, indicating that it is a secretory protein consistent with a function in the extracellular space (Takahashi et al. 1990; Avissar et al. 1994b).

\section{Gastrointestinal glutathione peroxidase (giGSHPx)}

giGSHPx has been identified by expression of a cDNA isolated from human hepatoma cells. Antibodies to giGSHPx do not cross react with either cGSHPx or plGSHPx; however, the properties and the structure of giGSHPx are very similar to those of cGSHPx. mRNA for giGSHPx is found in human liver and colon but not in other tissues; in rats the mRNA is detected only in the gastrointestinal tract. The function of this form of glutathione peroxidase has yet to be established but its location suggests a role in protecting against adverse effects of ingested hydroperoxides (Chu et al. 1993). 


\section{Phospholipid hydroperoxide glutathione peroxidase (PGSHPX)}

PGSHPx is different from the other glutathione peroxidases in that it is a monomer of approximately $20 \mathrm{kDa}$, it is less specific with regard to GSH as its reducing substrate, and it is closely associated with intracellular membranes (Ursini et al. 1985; Thomas et al. 1990; Maiorino et al. 1991a). Unlike cGSHPx, PGSHPx will react with phospholipid hydroperoxides which are likely to occur in cell membranes undergoing oxidative stress (Maiorino et al. 1991b). PGSHPx activity is better preserved in Se deficiency than are the other glutathione peroxidases, indicating that it may have a more important antioxidant function (Weitzel et al. 1990). The basis of the biochemical and nutritional interactions between Se and vitamin E may be the action of PGSHPx and the vitamin as antioxidants, preserving membrane lipid integrity.

The tissue distribution of PGSHPx is different from that of cGSHPx in particular; it is abundant in the testes and may be regulated by gonadotrophins (Roveri et al. 1992). PGSHPx also has a phosphorylation site which may have a role in regulation of enzyme activity (Schuckelt et al. 1991; BrigeliusFlohe et al. 1994). Potentially, therefore, PGSHPx may have a function in controlling metabolism rather than just being an antioxidant protecting against lipid peroxidation. Regulation of the levels of eicosanoid hydroperoxides by PGSHPx would influence many cell functions (Bryant $e t$ al. 1983; Cao et al. 1992: Weitzel \& Wendel, 1993).

\section{SELENOPROTEIN P}

Of plasma Se in humans and rodents $60-80 \%$ occurs as selenoprotein $\mathrm{P}$. The protein has been purified from rat and human plasma and cDNA clones have been prepared and sequenced (Yang et al. 1987; Hill et al. 1991, 1993; Akesson et al. 1994). In both cases the cDNA contains ten UGA codons in the open reading frame specifying ten selenocysteine residues. Additionally, selenoprotein $P$ contains twenty-three histidine residues and seventeen cysteine residues, indicating a great potential for binding free transition metals (Hill et al. 1991).

Despite detailed knowledge of its structure, the function of selenoprotein $\mathrm{P}$ has not been established. When Se-deficient rats are treated with Se the first selenoprotein -synthesized is selenoprotein P (Burk et al. 1991). This corresponds with protection against toxic effects of diquat, which causes hepatic necrosis in Se-deficient rats. Thus, it -has been suggested that selenoprotein $\mathrm{P}$ may have an antioxidant function, although initially it was hypothesized to be a Se-transport protein (Hill \& Burk, 1994). In Se-deficient rats there seems to be some selective uptake of injected selenoprotein $\mathrm{P}$ by the brain but there is no other direct evidence to support a transport function (Burk et al. 1991). It would be unusual to have a Se transport protein with such potential antioxidant properties and, furthermore, the energy required for its synthesis would be wasted since the selenocysteine in the protein would have to be returned to an inorganic form for synthesis of other selenoproteins. The same argument about waste of energy would apply to the hypothesis that cGSHPx is a Se storage protein. However, both selenoprotein $\mathrm{P}$ and cGSHPx may keep Se in a chemically-inactive form which will not interfere with redox-active thiols in the cell. 


\section{IODOTHYRONINE 5'-DEIODINASE (IDI)}

The observation that, in rats, plasma thyroxine (T4) concentrations increased and plasma 3,3',5-triiodothyronine (T3) concentrations decreased in Se deficiency led to the demonstration that this resulted from decreased hepatic type I IDI activity (Arthur et al. $1987 b, 1990 b$; Beckett et al. 1987, 1989, 1990, 1992). This work continued with the identification of IDI as a Se-containing protein (Arthur et al. 1990a, 1991, 1993). Conventional protein chemical techniques were used to prove that IDI contained one Se in each substrate-binding subunit and, using an expression cloning system, Berry and Larsen (Behne et al. 1990; Berry et al. 1991; Berry \& Larsen, 1992) demonstrated that IDI contained selenocysteine inserted via a UGA stop codon in a similar fashion to that of other selenoproteins. IDI activity in liver and kidney is regulated by Se supply in the normal nutritional range; thus, Se plays an important role in the control of thyroid hormone metabolism (Arthur \& Beckett, 1994). Decreases in plasma T3 concentration in Se deficiency, however, are less than might be predicted, which indicates that compensatory mechanisms ameliorate some of the adverse effects of the loss of IDI activity (Beckett et al. 1992, 1993b; Chanoine et al. 1992, 1993; Arthur et al. 1993). Nevertheless, in conditions such as I deficiency, where thyroid hormone metabolism is impaired, Se deficiency may provide an additional stress with possible adverse effects on growth development, thermogenesis and neonatal survival (Geloen et al. 1990; Beckett et al. 1993b; Nicol et al. 1994).

An important compensatory mechanism which preserves T3 in Se-deficient rats is increased thyroidal T3 production, probably coming from induction of thyroidal IDI, despite its being a selenoenzyme whose activity would be expected to decrease (Beckett et al. 1993a; Chanoine et al. 1993). Human thyroid also contains IDI activity and, thus, the potential to maintain $\mathrm{T} 3$ production from $\mathrm{T} 4$ when Se supplies are limiting (Beech et al. 1993). However, many species including ruminants and pigs do not express IDI in the thyroid and, thus, there may be major differences in the response of thyroid hormone metabolism to Se deficiency (Beech et al. 1993). Unless other mechanisms exist to preserve thyroidal T3 production, lack of IDI activity in the gland may confer greater susceptibility to the effects of Se deficiency on thyroid hormone metabolism.

\section{SPERM CAPSULE SELENOPROTEIN}

Se deficiency causes abnormal sperm development in the rat. Compared with normal rats, Se-deficient rats produce fewer spermatozoa and these have abnormal tails and are immobile (see Calvin et al. 1987). The abnormalities have been associated with more fragile mitochondrial capsules, which contain a major structural selenoprotein. The cDNA which codes for mouse mitochondrial capsule selenoprotein has three inframe UGA codons that probably code for selenocysteine and the predicted molecular weight of the protein is $21 \cdot 1 \mathrm{kDa}$ (Karimpour et al. 1992). This is the first protein subunit found, other than selenoprotein $\mathrm{P}$, which contains more than one selenocysteine. Sperm capsule selenoprotein also has six Pro-Cys-Cys-Pro sequences with eighteen to twenty cysteine residues and twenty-three to twenty-seven proline residues in total, which supports a structural role for the selenoprotein, since the intramolecular sulphydryl bonds will confer stability. Loss of this structure in Se deficiency would explain adverse effects on sperm function and lower fertility. Much work remains to be done, however, to confirm the function of the protein. 


\section{SELENOPROTEIN W}

Selenoprotein $\mathrm{W}$ is a low-molecular-weight protein $(9 \cdot 5-10 \cdot 0 \mathrm{kDa})$, of unknown function, which has been purified from rat muscle. It is believed to be similar to the low-molecular-weight selenoprotein that occurs in lamb muscle and which decreases in concentration during the onset of myopathy in combined Se and vitamin E deficiency. Selenoprotein W contains approximately $1 \mathrm{~g}$ atom Se/mol, as selenocysteine, at position 12 in its sequence. A partial amino acid sequence is not similar to any previously published sequences, indicating that selenoprotein $\mathrm{W}$ is not a fragment or subunit of one of the selenoglutathione peroxidases (Vendeland et al. 1993). Since selenoprotein W contains redox-active selenocysteine and occurs at concentrations similar to those of cGSHPx in heart and muscle it has been proposed that it may be an antioxidant. Until further investigations such as the response of the protein to Se depletion and repletion and further structural analysis are carried out, the antioxidant function can not be confirmed.

\section{SELENIUM-BINDING PROTEINS}

Proteins of $14 \mathrm{kDa}$ and $56 / 58 \mathrm{kDa}$ bind ${ }^{75} \mathrm{Se}$ both in vivo and in cell culture systems. Fatty acid-binding protein has been identified as the $14 \mathrm{kDa}$ Se-binding protein, and the 56 $\mathrm{kDa}$ protein is closely related to proteins which bind many drugs and their metabolites. The $58 \mathrm{kDa}$-binding protein shows sequence homology with protein disulphide isomerase. However, in mouse mammary epithelial cells in culture, changing medium Se concentration did not affect levels of the $58 \mathrm{kDa}$ protein (Sinha et al. 1993). Furthermore, Se does not regulate protein disulphide isomerase activity either in rats or in cultured cells (Arthur et al. 1991; Sinha et al. 1993). The Se-binding proteins have been hypothesized to have an anti-cancer effect; labelling of the $58 \mathrm{kDa}$ protein with ${ }^{75} \mathrm{Se}$ corresponded to inhibition of DNA synthesis by Se added to cell cultures and the $56 \mathrm{kDa}$ protein (SP56) may be involved in the regulation of cell growth by modulating regulatory proteins (Bansal et al. 1990; Sinha et al. 1993). However, since levels of the Se-binding proteins are not apparently regulated by availability of Se, more experimental information is required to define their function in vivo.

\section{CONCLUSIONS}

The identification, sequencing and cloning of several selenoproteins has indicated a hitherto unrecognized complexity in the biochemical roles of Se. Since dietary Se intake can affect many biological functions and processes, the challenge is now to relate these to the biochemistry of selenoproteins.

Se has clearly defined roles in antioxidant systems and in thyroid hormone metabolism but the precise functions of selenoprotein $P$, sperm capsule selenoprotein, selenoprotein $\mathrm{W}$ and the Se-binding proteins remain to be established. Additionally, in vivo and cell culture-labelling studies with ${ }^{75} \mathrm{Se}$ indicate that there are at least ten more selenoproteins to be characterized. Thus, although much is now known about the nutritional biochemistry of Se, the functions of many selenoproteins remain to be established. Only when this has been achieved will all consequences of changes in Se status be understood.

Work in the authors' laboratories was supported by the Scottish Office Agriculture and Fisheries Department (SOAFD) and the The Wellcome Trust. 


\section{REFERENCES}

Akesson, B., Bellew, T. \& Burk, R. F. (1994). Purification of selenoprotein P from human plasma. Biochimica et Biophysica Acta 1204, 243-249.

Arthur, J. R. (1991). The role of selenium in thyroid hormone metabolism. Canadian Journal of Physiology and Pharmacology 69, 1648-1652.

Arthur, J. R. \& Beckett, G. J. (1989). Selenium deficiency and thyroid hormone metabolism. In Selenium in Biology and Medicine, pp. 90-95 [A. Wendel, editor]. Heidelberg: Springer-Verlag.

Arthur, J. R. \& Beckett, G. J. (1994). Roles of selenium in type I iodothyronine 5 'deiodinase and in thyroid hormone and iodine metabolism. In Selenium in Biology and Human Health, pp. 93-115 [R. F. Burk, editor]. New York: Springer-Verlag.

Arthur, J. R., Boyne, R., Morrice, P. \& Nicol, F. (1986). Selenium and neutrophil function in mice. Proceedings of the Nutrition Society 45, 63A.

Arthur, J. R., Morrice, P. C., Nicol, F., Beddows, S. E., Boyd, R., Hayes, J. D. \& Beckett, G. J. (1987a). The effects of selenium and copper deficiencies on glutathione S-transferase and glutathione peroxidase in rat liver. Biochemical Journal 248, 539-544.

Arthur, J. R., Nicol, F. \& Beckett, G. J. (1990a). Hepatic iodothyronine deiodinase: The role of selenium. Biochemical Journal 272, 537-540.

Arthur, J. R., Nicol, F. \& Beckett, G. J. (1993). Selenium deficiency, thyroid hormone metabolism, and thyroid hormone deiodinases. American Journal of Clinical Nutrition 57, S236-S239.

Arthur, J. R., Nicol, F., Boyne, R., Allen, K. G. D.. Hayes, J. D. \& Beckett, G. J. (1987b). Old and new roles for selenium. In Trace Substances in Environmental Health XXI, pp. 487-498 [D. D. Hemphill, editor]. Colombia: University of Missouri.

Arthur, J. R., Nicol, F., Grant, E. \& Beckett, G. J. (1991). The effects of selenium deficiency on hepatic type-I iodothyronine deiodinase and protein disulphide-isomerase assessed by activity measurements and affinity labelling. Biochemical Journal 274, 297-300.

Arthur, J. R., Nicol, F., Hutchinson, A. R. \& Beckett, G. J. (1990b). The effects of selenium depletion and repletion on the metabolism of thyroid hormones in the rat. Journal of Inorganic Biochemistry 39, 101-108.

Avissar, N., Kerl, E. A., Baker, S. S. \& Cohen, H. J. (1994a). Extracellular glutathione peroxidase mRNA and protein in human cell lines. Archives of Biochemistry and Biophysics 309, 239-246.

Avissar, N., Ornt, D. B., Yagil, Y., Horowitz, S., Watkins, R. H., Kerl, E. A., Takahashi, K., Palmer, I. S. \& Cohen, H. J. (1994b). Human kidney proximal tubules are the main source of plasma glutathione peroxidase. American Joumal of Physiology 266, C367-C375.

Avissar, N., Slemmon, J. R., Palmer, I. S. \& Cohen, H. J. (1991). Partial sequence of human plasma glutathione peroxidase and immunologic identification of milk glutathione peroxidase as the plasma enzyme. Joumal of Nutrition 121, 1243-1249.

Avissar, N., Whitin, J. C., Allen, P. Z., Wagner, D. D., Liegey, P. \& Cohen, H. J. (1989). Plasma selenium-dependent glutathione peroxidase - cell of origin and secretion. Journal of Biological Chemistry 264, 15850-15855.

Bansal, M. P., Ip, C. \& Medina, D. (1991). Levels and Se-75-labeling of specific proteins as a consequence of dietary selenium concentration in mice and rats. Proceedings of the Society for Experimental Biology and Medicine 196, 147-154.

Bansal, M. P., Mukhopadhyay, T., Scott, J., Cook, R. G., Mukhopadhyay, R. \& Medina, D. (1990). DNA sequencing of a mouse liver protein that binds selenium - implications for selenium's mechanism of action in cancer prevention. Carcinogenesis 11, 2071-2073.

Beckett, G. J., Beddows, S. E., Morrice, P. C., Nicol, F. \& Arthur, J. R. (1987). Inhibition of hepatic deiodination of thyroxine caused by selenium deficiency in rats. Biochemical Journal 248, 443-447.

Beckett, G. J., Beech, S., Nicol, F., Walker, S. W. \& Arthur, J. R. (1993a). Species differences in thyroidal iodothyronine deiodinase expression and the effect of selenium deficiency on its activity. Journal of Trace Elements and Electrolytes in Health and Disease 7, 123-124.

Beckett, G. J., MacDougall, D. A., Nicol, F. \& Arthur, J. R. (1989). Inhibition of type I and type II iodothyronine deiodinase activity in rat liver, kidney and brain produced by selenium deficiency. Biochemical Journal 259, 887-892.

Beckett, G. J., Nicol, F., Proudfoot, D., Dyson, K., Loucaides, G. \& Arthur J. R. (1990). The cbanges in hepatic enzyme expression caused by selenium deficiency and hypothyroidism in rats are caused by independent mechanisms. Biochemical Journal 266, 743-747. 
Beckett, G. J., Nicol, F., Rae, P. W. H., Beech, S., Guo, Y. \& Arthur, J. R. (1993b). Effects of combined iodine and selenium deficiency on thyroid hormone metabolism in rats. American Journal of Clinical Nutrition 57, S240-S243.

Beckett, G. J., Russell. A., Nicol, F., Sahu, P., Wolf, C. R. \& Arthur, J. R. (1992). Effect of selenium deficiency on hepatic type-I 5-iodothyronine deiodinase and hepatic thyroid hormone levels in the rat. Biochemical Journal 282, 483-486.

Beech, S. G., Walker, S. W., Dorrance, A. M., Arthur, J. R., Nicol, F., Lee, D. \& Beckett, G. J. (1993). The role of thyroidal type-I iodothyronine deiodinase in tri-iodothyronine production by human and sheep thyrocyres in primary culture. Journal of Endocrinology 136, 361-370.

Behne, D., Hilmert, H., Scheid. S., Gessner, H. \& Elger, W. (1988). Evidence for specific selenium target tissues and new biologically important selenoproteins. Biochimica et Biophysica Acta 966, 12-21.

Behne, D., Kyriakopoulos, A., Meinhold, H. \& Kohrle, J. (1990). Identification of type-I iodothyronine $5^{\prime}$-deiodinase as a selenoenzyme. Biochemical and Biophysical Research Communications 173, 1143-1149.

Benton, D. \& Cook, R. (1990). Selenium supplementation improves mood in a double-blind crossover trial. Psychopharmacology 102, 549-550.

Benton, D. \& Cook, R. (1991). The impact of selenium supplementation on mood. Biological Psychiatry 29. $1092-1098$.

Berry, M. J., Banu, L. \& Larsen, P. R. (1991). Type-I iodothyronine deiodinase is a selenocysteine-containing enzyme. Nature 349, 438-440.

Berry, M. J. \& Larsen, P. R. (1992). The role of selenium in thyroid hormone action. Endocrine Reviews 13, 207-219.

Boyne, R. \& Arthur, J. R. (1986). The response of selenium deficient mice to Candida albicans infection. Journal of Nutrition 116, 816-822.

BrigeliusFlohe, R., Aumann, K. D., Blocker, H., Gross, G., Kiess, M., Kloppel, K. D., Maiorino, M., Roveri, A., Schuckelt, R., Ursini, F., Wingender, E. \& Flohe, L. (1994). Phospholipid-hydroperoxide glutathione peroxidase - genomic DNA, cDNA, and deduced amino acid sequence. Journal of Biological Chemistry 269, 7342-7348.

Bryant, R. W., Simon, T. C. \& Bailey, J. M. (1983). Hydroperoxy fatty acid formation in selenium deficient rat platelets: coupling of glutathione peroxidase to the lipoxygenase pathway. Biochemical and Biophysical Research Communications 117, 183-189.

Burk, R. F. (1989). Recent developments in trace element metabolism and function: Newer roles of selenium in nutrition. Journal of Nutrition 119, 1051-1054.

Burk, R. F. (1991). Molecular biology of selenium with implications for its metabolism. FASEB Journal 5, 2274-2279.

Burk, R. F. \& Hill, K. E. (1993). Regulation of selenoproteins. Annual Review of Nutrition 13. 65-81.

Burk, R. F., Hill, K. E., Read, R. \& Bellew, T. (1991). Response of rat selenoprotein-P to selenium administration and fate of its selenium. American Journal of Physiology 261, E26-E30.

Calvin, H. I., Grosshans, K., Musicant-Shikora, S. R. \& Turner, S. I. (1987). A developmental study of rat sperm and testis selenoproteins. Journal of Reproduction and Fertility 81, 1-11.

Cao, Y. Z., Maddox, J. F., Mastro, A. M., Scholz, R. W., Hildenbrandt, G. \& Reddy, C. C. (1992). Selenium deficiency alters the lipoxygenase pathway and mitogenic response in bovine lymphocytes. Journal of Nutrition 122, 2121-2127.

Chanoine, J. P., Braverman, L. E., Farwell. A. P., Safran, M., Alex, S., Dubord, S. \& Leonard, J. L. (1993). The thyroid gland is a major source of circulating-T(3) in the rat. Journal of Clinical Investigation 91, 2709-2713.

Chanione, J. P., Safran, M., Farwell, A. P., Dubord, S., Alex, S., Stone, S., Arthur, J. R., Braverman, L. E. \& Leonard, J. L. (1992). Effects of selenium deficiency on thyroid hormone economy in rats. Endocrinology 131, 1787-1792.

Chu, F. F., Doroshow, J. H. \& Esworthy, R. S. (1993). Expression, characterisation and tissue distribution of a new cellular selenium-dependent glutathione peroxidase, GSHPx-GI. Journal of Biological Chemistry 268, 2571-2576.

Combs, G. F. \& Combs, S. B. (1986). The Role of Selenium in Nutrition. New York: Academic Press Inc.

Corvilain, B., Contempre, B., Longombe, A. O., Goyens, P., Gervydecoster, C., Lamy, F., Vanderpas, J. B. \& Dumont, J. E. (1993). Selenium and the thyroid: how the relationship was established. American Journal of Clinical Nurrition 57, S244-S248.

Doroshow, J. H., Akman, S., Esworthy, S., Chu, F. F. \& Burke, T. (1991). Doxorubicin resistance conferred by selective enhancement of intracellular glutathione peroxidase or superoxide dismutase content in human MCF-7 breast cancer cells. Free Radical Research Communications 12, 779-781. 
Evenson, J. K. \& Sunde, R. A. (1988). Selenium incorporation into selenoproteins in the Se-adequate and Se-deficient rat. Proceedings of the Society for Experimental Biology and Medicine 187, 169-180.

Geloen, A., Arthur, J. R., Beckett, G. J. \& Trayhurn, P. (1990). Effect of selenium and iodine deficiency on the level of uncoupling protein in brown adipose tissue of rats. Biochemical Society Transactions 18 , 1269-1270.

Hill, K. E. \& Burk, R. F. (1994). Selenoprotein P - an extracellular protein containing multiple selenocysteines. In Selenium in Biology and Human Health, pp. 117-131 [R. F. Burk, editor]. New York: Springer-Verlag.

Hill, K. E., Lloyd, R. S. \& Burk, R. F. (1993). Conserved nucleotide sequences in the open reading frame and 3' untranslated region of selenoprotein-P messenger RNA. Proceedings of the National Academy of Sciences, USA 90, 537-541.

Hill, K. E., Lloyd, R. S., Yang, J. G., Read, R. \& Burk, R. F. (1991). The cDNA for rat selenoprotein-P contains 10 TGA codons in the opening reading frame. Journal of Biological Chemistry 266, 10050-10053.

Hoekstra, W. G. (1975). Biochemical function of selenium and its relation to vitamin E. Federation Proceedings 34, 2083-2089.

Ip, C. \& Lisk, D. J. (1994). Characterization of tissue selenium profiles and anticarcinogenic responses in rats fed natural sources of selenium-rich products. Carcinogenesis 15, 573-576.

Karimpour, I., Cutler, M., Shih, D., Smith, J. \& Kleene, K. C., (1992). Sequence of the gene encoding the mitochondrial capsule selenoprotein of mouse sperm: identification of three in-phase TGA selenocysteine codons. DNA and Cell Biology 11, 693-699.

Lanfear, J., Fleming, J., Walker, M. \& Harrison, P. (1993). Different patterns of regulation of the genes encoding the closely related $56-\mathrm{kDa}$ selenium-binding and acetaminophen-binding proteins in normal tissues and during carcinogenesis. Carcinogenesis 14, 335-340.

Maiorino, M., Chu, F. F., Ursini, F., Davies, K. J. A., Doroshow, J. H. \& Esworthy, R. S. (1991a). Phospholipid hydroperoxide glutathione peroxidase is the $18-\mathrm{kDa}$ selenoprotein expressed in human tumor cell lines. Journal of Biological Chemistry 266, 7728-7732.

Maiorino, M., Thomas, J. P., Girotti, A. W. \& Ursini, F. (1991b). Reactivity of phospholipid hydroperoxide glutathione peroxidase with membrane and lipoprotein lipid hydroperoxides. Free Radical Research Communications 12, 131-135.

Mirault, M. E., Tremblay, A., Beaudoin, N. \& Tremblay, M. (1991). Overexpression of seleno-glutathione peroxidase by gene transfer enhances the resistance of T47D human breast cells to clastogenic oxidants. Journal of Biological Chemistry 266, 20752-20760.

Nicol, F., Lefranc, H., Arthur, J. R. \& Trayhurn, P. (1994). Characterisation of Type I deiodinase in goat brown adipose tissue. American Journal of Physiology 267, R144-R149.

Reiter, R. \& Wendel, A. (1983). Selenium and drug metabolism-I, Multiple modulations of mouse liver enzymes. Biochemical Pharmacology 32, 3063-3067.

Reiter, R. \& Wendel, A. (1984). Selenium and drug metabolism-II, Independence of glutathione peroxidase and reversibility of hepatic enzyme modulations in deficient mice. Biochemical Pharmacology 33, 1923-1928.

Reiter, R. \& Wendel, A. (1985). Selenium and drug metabolism-III, Relation of glutathione peroxidase and other hepatic enzyme modulations to dietary supplements. Biochemical Pharmacology 34, 2287-2290.

Rotruck, J. T., Pope, A. L., Ganther, H. E., Swanson, A. B., Hafeman, D. G. \& Hoekstra, W. G. (1973). Selenium: biochemical role as a component of glutathione peroxidase. Science 179, 588-590.

Roveri, A., Casasco, A., Maiorino, M., Dalan, P., Calligaro, A. \& Ursini, F. (1992). Phospholipid hydroperoxide glutathione peroxidase of rat testis - gonadotropin dependence and immunocytochemical identification. Journal of Biological Chemistry 267, 6142-6146.

Schuckelt, R., BrigeliusFlohe, R., Maiorino, M., Roveri, A., Reumkens, J., Strassburger, W., Ursini, F., Wolf, B. \& Flohe, L. (1991). Phospholipid hydroperoxide glutathione peroxidase is a seleno-enzyme distinct from the classical glutathione peroxidase as evident from $\mathrm{cDNa}$ and amino acid sequencing. Free Radical Research Communications 14, 343-361.

Sinha, R., Bansal, M. P., Ganther, H. \& Medina, D. (1993). Significance of selenium-labelled proteins for selenium's chemopreventive functions. Carcinogenesis 14, 1895-1900.

Sunde, R. A. (1990). Molecular biology of selenoproteins. Annual Review of Nutrition 10, 451-474.

Sunde, R. A. (1994). Intracellular glutathione peroxidases - structure regulation and function. In Selenium in Biology and Human Health, pp. 45-77 [R. F. Burk, editor]. New York: Springer-Verlag.

Sunde, R. A., Dyer, J. A., Moran, T. V., Evenson, J. K. \& Sugimoto, M. (1993). Phosopholipid hydroperoxide glutathione peroxidase - full-length pig blastocyst cDNA sequence and regulation by selenium status. Biochemical and Biophysical Research Communications 193, 905-911. 
Takahashi, K., Akasaka, M., Yamamoto, Y., Kobayashi, C., Mizoguchi, J. \& Koyama, J. (1990). Primary structure of human plasma glutathione peroxidase deduced from cDNA sequences. Journal of Biochemistry 108, 145-148.

Takahashi, K., Avissar, N., Whitin, J. \& Cohen, H. (1987). Purification and characterization of human plasma glutathione peroxidase: A selenoglycoprotein distinct from the known cellular enzyme. Archives of Biochemistry and Biophysics 256, 677-686.

Takahashi, K. \& Cohen, H. J. (1986). Selenium-dependent glutathione peroxidase protein and activity: Immunological investigations on cellular and plasma enzymes. Blood 68, 640-645.

Thomas, J. P., Maiorino, M., Ursini, F. \& Girotti, A. W. (1990). Protective action of phospholipid hydroperoxide glutathione peroxidase against membrane-damaging lipid peroxidation - in situ reduction of phospholipid and cholesterol hydroperoxides. Journal of Biological Chemistry 265, 454-461.

Tumer, R. J. \& Finch, J. M. (1990). Immunological malfunctions associated with low selenium vitamin-E diets in lambs. Journal of Comparative Pathology 102, 99-109.

Turner, R. J. \& Finch, J. M. (1991). Selenium and the immune response. Proceedings of the Nutrition Society 50, 275-285

Ursini, F., Maiorino, M. \& Gregolin, C. (1985). The selenoenzyme phospholipid hydroperoxide glutathione peroxidase. Biochimica et Biophysica Acta 839, 62-70.

Vanderpas, J. B., Contempre, B., Duale, N. L., Deckx, H., Bebe, N., Longombe, A. O., Thilly, C. H., Diplock, A. T. \& Dumont, J. E. (1993). Selenium deficiency mitigates hypothyroxinemia in iodinedeficient subjects. American Journal of Clinical Nutrition 57, S271-S275.

Vanderpas, J. B., Contempre, B., Duale, N. L., Goossens, W., Bebe, N., Thorpe, R., Ntambue, K., Dumont, J. E., Thilly, C. H. \& Diplock, A. T. (1990). Iodine and selenium deficiency associated with cretinism in northern Zaire. American Journal of Clinical Nutrition 52, 1087-1093.

Vendeland, S. C., Beilstein, M. A., Chen, C. L., Jensen, O. N., Barofsky, E. \& Whanger, P. D. (1993). Purification and properties of selenoprotein-W from rat muscle. Journal of Biological Chemistry 268, 17103-17107.

Weitzel, F., Ursini, F. \& Wendel, A. (1990). Phospholipid hydroperoxide glutathione peroxidase in various mouse organs during selenium deficiency and repletion. Biochimica et Biophysica Acta 1036, 88-94.

Weitzel, F. \& Wendel, A. (1993). Selenoenzymes regulate the activity of leukocyte 5-lipoxygenase via the peroxide tone. Journal of Biological Chemistry 268, 6288-6292.

Yang, J.-G., Morrison-Plummer, J. \& Burk, R. F. (1987). Purification and quantitation of a rat plasma selenoprotein distinct from glutathione peroxidase using monoclonal antibodies. Journal of Biological Chemistry 262, 13372-13375.

Yoshimura, S., Watanabe, K., Suemizu, H., Onozawa, T., Mizoguchi, J., Tsuda, K., Hatta, H. \& Moriuchi, T. (1991). Tissue specific expression of the plasma glutathione peroxidase gene in rat kidney. Journal of Biochemistry 109, 918-923. 